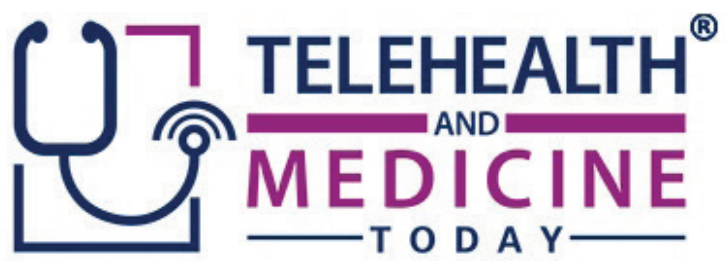

\title{
Predictions for Telehealth in 2020: Will This be the Takeoff Year?
}

Amar Gupta ${ }^{1,2}$, Mike Baird ${ }^{3}$, Shayan Vyas ${ }^{4,5}$, Joel Reich ${ }^{6}$, Stephanie Zawada ${ }^{7}$, Sumit Nagpal ${ }^{8}$, Oren J. Mechanic ${ }^{9,10,11}$

Affiliation: ${ }^{1}$ MIT's Institute of Medical Engineering and Science (IMES), USA; ${ }^{2}$ Telehealth and Medicine Today; ${ }^{3}$ Customer Solutions, American Well, Reston, VA, USA; ${ }^{4}$ VP Quality and Innovations, Teladoc Health; ${ }^{5}$ Pediatrics, University of Central Florida College of Medicine, USA; ${ }^{6} \mathrm{Health}$ Tech Consultant/Graduate level Population Health, Healthcare Economics \& Health Care Leadership Instructor, USA; ${ }^{7}$ American Medical Students Association, USA; ${ }^{8}$ Global GM, Health Innovation, Comcast NBCUniversal, USA; ${ }^{9}$ Harvard Medical School; ${ }^{10}$ Department of Emergency Medicine, Beth Israel Deaconess Medical Center; ${ }^{11}$ Telehealth, Harvard Medical Faculty Physicians, Boston, MA, USA

Corresponding Author: Amar Gupta, agupta@mit.edu

Keywords: Asynchronous Communication, Asynchronous Medical Visit, Behavioral Health, Concierge Medicine, Connect 3.0, Cybersecurity, HER, Healthcare Interoperability, Remote Care, Remote Patient Monitoring, RPM, Telehealth, Value-Based Care

Section: Narrative/Systematic Reviews/Meta-Analysis

\section{INTRODUCTION BY AMAR GUPTA}

In order to place predictions for telehealth in proper perspective, consider that like all new industries, telehealth is characterized by disparate ideas developed by different people, often for the same medical specialty and/or medicine-related activity. Over time, these ideas must coalesce to provide growth and economies of scale. This occurs at multiple levels. One need only look at the history of banking and finance for an analogous situation that is highlighted by innovation, mergers, and integration.

In healthcare, the overall experience with an array of disparate health information exchanges has been less than satisfactory for most observers. While the trend towards consolidation has begun in the telehealth arena, it is at an early stage.

With this in mind, our invited experts looked into the future from their shared and unique perspectives to offer their view on the next big thing(s) in telehealth in 2020.

\section{MIKE BAIRD}

Four major events will mark the continuing growth of telehealth during 2020. We will see changes from a regulatory and legislative front, product improvements, new market entrants, and the expansion of telehealth services. 
First, the Connect for Health Act (in its third version!) will be finally passed with strong bipartisan support as the Congress wants to show some progress in a crazy election or impeachment year.

Second, remote patient monitoring (RPM) will become more relevant, with expanded reimbursement and adoption by health plans and the increasing adoption of the BYOD (bring your own device) model versus the historical hub and widget approach.

Third, we will see an explosion in telebehavioral health tied to increasing consumer demand for counseling, life coaching, posttraumatic stress syndrome (PTSD), emergency department (ED) or acute care coverage, wellness, and even helping address the opioid epidemic.

Finally, I think the industry will inevitably see greater consolidation of vendors in the industry. The increasing demands of employers, health plans, and health systems that are starting to use telehealth at scale have foundational requirements that cannot be met by smaller, semi-custom vendors. We may even see the entry of large-scale consumer tech companies (e.g., Google) via acquisition or product launches of their own. Either way, telehealth will continue to explode as one of the great drivers for improving healthcare in the next decade.

\section{SHAYAN VYAS}

Virtual care will continue to expand exponentially, particularly with hospitals and health systems.

Non-physician healthcare providers (e.g., advanced care providers [ACPs], counselors) will outpace physician's adoption of telehealth.
RPM and asynchronous telehealth will start to become popular and standard of care for highrisk patients.

\section{OREN J. MECHANIC}

Telehealth provides an important tool for valuebased medical care to our patients. In 2020, I suspect that the US and international healthcare systems will continue to adopt novel, innovative and sustainable digital means, with the goal of providing accessible, quality-driven, and convenient care.

During the past few years, we established the groundwork for digital health implementation. In 2020, we will continue to work on bettering patient health outcomes while maintaining increased healthcare costs. Its scientific study will be augmented as a modern healthcare delivery modality and science.

\section{JOEL REICH}

In 2020 we will see continuing slow but steady transformation from fee-for-service payment to value-based payment. As the model shifts, we will use telehealth as both a fee-for-service revenue stream and a value-based cost-avoidance tool. Areas that will be impacted are listed in Table 1.

\section{STEPHANIE ZAWADA}

Cybersecurity in telehealth and RPM will be a high priority in 2020. Security regulations for telemedicine expansion were discussed in July 2019 before the Massachusetts House of Representatives Committee on Technology and Intergovernmental Affairs. ${ }^{1}$ Also in July 2019, UC San Diego Health appointed the nation's first medical director of cybersecurity. ${ }^{2}$

At the FDA's Patient Engagement Advisory Committee in September 2019, it was established that cybersecurity training "ought to 
Table 1. Anticipated contribution of telehealth from fee-for-service payment to value-based payment

\begin{tabular}{|c|c|}
\hline Facet of healthcare & Contribution \\
\hline Clinical decision-making & $\begin{array}{l}\text { Address issues regarding the effect of telemedicine on clinical decision- } \\
\text { making (e.g., antibiotic utilization), as well as how to optimize the flow of } \\
\text { data into patients' EHR }\end{array}$ \\
\hline $\begin{array}{l}\text { Detection of changes in } \\
\text { clinical status }\end{array}$ & $\begin{array}{l}\text { Clinically integrated networks and ACOs recognize the power of direct care } \\
\text { provider-to-patient telemedicine for early detection of clinical status change } \\
\text { and avoidance of ED visits, as well as freeing up office appointment slots } \\
\text { for fee-for-service patients }\end{array}$ \\
\hline Billing & $\begin{array}{l}\text { New CPT billing codes enhance reimbursement under fee-for-service } \\
\text { payment }\end{array}$ \\
\hline Reimbursement & Expand traditional or original Medicare payment for telehealth services \\
\hline Medicare Advantage & Medicare Advantage Plans permit funds for telehealth or telemedicine \\
\hline Community-based care & $\begin{array}{l}\text { Growth of community-based care management and clinical response teams } \\
\text { enable the success of remote patient monitoring (RPM), that is, technology } \\
\text { alone will not succeed unless deployed within a functional system that } \\
\text { responds to changes in clinical status }\end{array}$ \\
\hline Remote monitoring & $\begin{array}{l}\text { Remote patient monitoring technology continues to evolve and enhance } \\
\text { patient experience while reducing clinical and technical staff support }\end{array}$ \\
\hline $\begin{array}{l}\text { Convergence of } \\
\text { technologies }\end{array}$ & $\begin{array}{l}\text { Convergence of several technologies including provider-to-patient } \\
\text { telemedicine, RPM and smart speakers with AI technology enhance care in } \\
\text { remote settings, including extending access to behavioral health services }\end{array}$ \\
\hline
\end{tabular}

ACO, accountable care organisation; AI, artificial technology; CPT, current procedural technology; ED, emergency department; EHR, electronic health record.

be increasingly incorporated into medical, pharmacy and nursing school curricula, particularly in device-heavy specialties like cardiology or nephrology." 3

Telehealth as a mode of direct primary careand concierge medicine-delivery will become more popular. Primary care services that are accessible via telehealth are increasingly viewed as a cost-effective option for reducing unnecessary ED visits without compromising patient outcomes. Multiple 24/7 concierge medicine companies that offer coordinated care services saw exponential growth in 2019 and are expected to expand their market share in $2020 .^{4}$
The growing popularity of using a health savings account (HSA) and a flexible spending account (FSA) to cover out-of-pocket routine or unexpected medical bills dovetails the shift towards direct and concierge health services that do not take insurance plans. ${ }^{5}$ As more concierge telemedicine options are launched, the interoperability of healthcare records will become more important, particularly for coordinating care between providers throughout the disease-management process.

As more states move to expand telemedicine reimbursement (e.g., Arizona, California, Florida), the role of telehealth in equitable and personalized healthcare will take center stage.$^{6-8}$ 
For rural Americans, virtual ED and telepsychiatry services, sometimes the only options for medical care, are on the rise. ${ }^{9}$

With the expansion of $5 \mathrm{G}$ networks, the use of augmented reality in telemedicine has emerged as viable, a considerable improvement for expanding access to care for patients with disabilities. ${ }^{10}$ Researchers at Cornell Tech, MIT and Massachusetts General Hospital, for example, found that augmented reality recognition systems that "bring the expert 'eyes' to patients' homes" can improve disease management. ${ }^{11}$ For Medicare Advantage seniors, new 2020 plans will offer telehealth reimbursements, at-home services and transportation to appointments. ${ }^{12}$ Telehealth will play a crucial role in removing access barriers to healthcare for the aging, disabled, and rural Americans in 2020.

The 2020 Physician Fee Schedule is projected to expand the use of RPM, potentially opening the way for new apps and devices that capture patient data in real-time for more robust decision-making by remote providers. ${ }^{13}$ Jogo Health, for instance, has raised over 2 million USD (1.8 million EUR) by using its software platform that trains the brain to regain muscle function after a stroke, a tool known as a prescription digital therapeutic. ${ }^{14}$ The 2020 Physician Fee Schedule also includes new telehealth codes specific for the treatment of opioid use disorders. ${ }^{15}$

\section{SUMIT NAGPAL}

Telehealth will transition from being about remote care to being about enabling us to live more safely and longer in our own homes, without having to give up our independence, relationships and possessions as we age and live longer.

Telehealth applications addressing behavioral health and social isolation will once and for all change our ability to support people and bring more joy into their lives as they live longer with dementia and Alzheimer's disease.

Telehealth solutions will evolve from today's wearables, sensors and digital applications that require attention to deliver their benefits to ones that are integrated into our homes and lifestyles and support us ambiently, without extra effort.

Telehealth solutions will be able to address data access, privacy and security issues so that people willingly adopt highly personalized offerings that leverage everything to know about us in a "marketplace of one" to support and enthrall us.

\section{ASSESSMENTS AND CONCLUSIONS (AMAR GUPTA)}

Ten years ago, the annual predictions for telehealth consisted entirely of technical issues. In contrast, and as a sign of progress, the above predictions span technical, billing, cybersecurity, and allied issues.

The next stage in the evolution of this nascent industry has begun. Broad deployment will require close coordination among people with policy, medical, legal, technical, business, and economic backgrounds. In the case of the geographic areas that are leading in deployment of telehealth, it is the academia, industry, and government that must work closely to develop, refine, and implement solutions that cater to larger number of patients and medical specialties. This is promising as similar types of industrygovernment-academic collaborations have served as catalysts for change in their spheres of activity (e.g., in finance, banking).

Adoption of 5G communication systems will further highlight the growing need to transform the disparate islands of healthcare information emanating from Internet-of-Things (IoT) devices, 
localized electronic health record (EHR) systems, national-or geographically-based pharmacy systems, and other systems into an integrated archipelago of valuable knowledge.

While the need for a unified approach for healthcare interoperability will be more broadly recognized, no substantive progress will be made during 2020, because of lack of leadership and diversity in priority among the major constituencies. The current approaches to healthcare interoperability are focused on specific niches of healthcare industry (EHR, medical devices, pharmacy, or even smaller niches) or a relatively small segment of the global population, and this will continue to be a major hurdle.

One area that deserves mention here is the state of practice of telehealth across man-made boundaries - organizational as well as political. The issue of organizational boundaries will be partially mitigated by mergers and acquisitions of hospitals, medical clinics, and other healthcare organizations, but the problems associated with sharing data require greater coordination between industry, government, and academia. In the context of practice of telehealth across states in the USA, the opinion expressed in 2011 that laws and regulations enacted by state governments violated the interstate commerce clause of the US constitution is reflected in the new nationwide policy on telehealth formulated by the Department of Veterans Affairs. ${ }^{16}$ However, other agencies of the federal government and most agencies of state governments of the USA must take similar action.

While telehealth can be evaluated in terms of quality of healthcare, speed of providing access to a medical professional in the concerned medical specialty and initiation of treatment, and the cost involved, action is needed at legal and policy levels to support the evolving telehealth techniques. Further, newer mechanisms must be evolved to look at the quality and safety of new mechanisms independently and to have systematic ways of retraining artificial neural networks and other AI and machine learning (ML) techniques at periodic intervals based on newer data from patients from diverse ethnic and cultural backgrounds.

While the practice of asynchronous telehealth across continents has evolved over the last 25 years starting with reading of radiological images, the use of synchronous telehealth was earlier mooted as a mechanism to improve the safety and quality of healthcare by enabling doctors and other medical professionals to get adequate and proper sleep at regular hours during nighttime. This concept is being gradually adopted. Emory Healthcare uses this in the context of tele-ICU systems with doctors and other medical personnel working during daytime in Australia to look after patients during nighttime in Atlanta.

Countries in Europe are also taking proactive steps to foster telehealth between themselves. This includes looking at health data privacy regulations across nations taking into account the large percentage of population that travels between European countries each year. The issue of health data privacy requires coordinated action at the global level and lack of activity in this arena will continue to retard the pace of deployment of technologies and procedures articulated by the visionaries in the preceding section of this article.

The success of national and trans-national telehealth endeavors will reinforce the critical requirement for delineating and using an integrated strategy that involves experts in 
medical, technical, legal, economic, policy, and strategy areas on a peer basis.

With the growing realization that enhanced interdisciplinary collaboration and pragmatic coordinated approach to interoperability are critical success factors for success and growth, the pace of innovation and deployment in telehealth arena will be significantly faster in the new year.

Overall, 2020 will indeed be the Takeoff Year for telehealth in several countries but not universally.

\section{Conflicts of Interest}

See TMT Editorial Team for information about authors: https://telehealthandmedicinetoday.com/ index.php/journal/about/editorialTeam

\section{Contributors}

Each author prepared their respective sections of this article.

\section{Funding statement}

No funding was provided for this article.

\section{REFERENCES}

1. Rhoads J. Testimony to the Massachusetts House of Representatives on telemedicine and cybersecurity. Mercatus Center; 2019. Available from: https:// www.mercatus.org/system/files/ rhoads_-_testimony___telemedicine testimony__-massachusetts_house_of_ representatives_-july_18_2019___v1.pdf

2. Haglund M. First in U.S. Healthcare: UC San Diego Health appoints a medical director of cybersecurity. Healthcare Innovation; 2019. Available from: https://www.hcinnovationgroup.com/ cybersecurity/medical-device-security/ article/21091447/first-in-us-healthcareuc-san-diego-health-appoints-a-medicaldirector-of-cybersecurity

3. Rachal M. US needs cyber-savvy doctors as connected device use rises, FDA panel say. MedtechDive; 2019. Available from: https://www.medtechdive.com/ news/us-needs-cyber-savvy-doctors-asconnected-device-use-rises-fda-panelsays/562658/

4. Young L. This Troy telemedicine company doubled revenue three straight years. Why its CEO expects to do it again in 2020. Albany Business Review. 2019. Available from: https://www.bizjournals. com/albany/news/2019/11/11/unitedconcierge-medicine-er-anywhere-growth. html, https://www.bizjournals.com/ kansascity/news/2019/11/05/oscarhealth-insurance-telemedicine-primarycare.html

5. Leonhardt M. If you have access to an FSA or HSA, here's why you should sign up for one this year. Make It. 2019. Available from: https:/www.cnbc.com/2019/10/29/ how-fsa-hsa-can-save-you-money-onmedical-costs.html

6. Lacktman NM. Arizona governor signs new telehealth insurance Law. Foley\& Lardner LLP; 2019. Available from: https://www. foley.com/en/insights/publications/2019/04/ arizona-governor-signs-new-telehealthinsurance-la

7. Ferrante TB, Lacktman NM. Florida Legislature passes new telehealth law. Foley \& Lardner, LLP; 2019. Available from: https://www.foley.com/en/insights/ publications/2019/05/florida-legislaturepasses-new-telehealth-law

8. Ferrante TB, Lacktman NM. California governor signs new telehealth insurance law. Foley \& Lardner, LLP; 2019. Available from: https://www.foley.com/en/insights/ publications/2019/10/california-governornew-telehealth-insurance-law

9. Saslo E. The most remote emergency room: Life and death in rural America. The Washington Post. 2919. Available from: https://www.washingtonpost.com/ national/the-most-remote-emergencyroom/2019/11/16/717d08e2-063e11ea-b17d-8b867891d39d_story.html, https://www.aamc.org/news-insights/ 
doctor-will-skype-you-now-onlinecounseling-goes-high-tech

10. O'Halloran J. University Hospitals Birmingham demos UK's first remote 5G-powered diagnostic procedure. Computer Weekly.com. 2019. Available from: https://www.computerweekly.com/ news/252474047/University-HospitalsBirmingham-demos-UKs-first-remote-5Gpowered-diagnostic-procedure

11. Hachuel D, Jha A, Staller K, et al. Augmenting gastrointestinal health: A deep learning approach to human stool recognition and characterization in macroscopic images. 2019. Available from: https://arxiv.org/ftp/arxiv/ papers/1903/1903.10578.pdf

12. Sisson P. From transportation to telemedicine, 2020 brings an explosion of fringe benefits to Medicare. The San Diego Union-Tribune 2019. Available from: https://www.sandiegouniontribune. com/news/health/story/2019-11-13/ from-transportation-to-telemedicine2020-brings-an-explosion-of-fringebenefits-to-medicare

13. Wein EH, Lacktman NM, Ferrante TB. Remote patient monitoring: Medicare proposes two major expansions. Foley \& Lardner LLP; 2019. Available from: https://www.foley.com/en/insights/ publications/2019/08/remote-patientmonitoring-medicare-expansions

14. Newmarker C. Digital therapeutics company Jogo Health raises \$2 million. Mass Device. 2019. Available from: https:// www.massdevice.com/digital-therapeuticscompany-jogo-health-raises-2-million/

15. Gupta A, Sando S, Parthasarthy S, Quan, S. Information technology conduit as a portal to circumvent the graveyard shift. J Clin Sleep Med. 2010;6(2):113-116.

16. Gupta A, Dogar ME, Zhai ES, et al. Innovative telemedicine approaches in different countries: Opportunity for adoption, leveraging, and scaling-up. Telehealth Med Today. In press 2020.

Copyright Ownership: This is an open access article distributed in accordance with the Creative Commons Attribution Non Commercial (CC BY-NC 4.0) license, which permits others to distribute, adapt, enhance this work non-commercially, and license their derivative works on different terms, provided the original work is properly cited and the use is noncommercial. See: http://creativecommons. org/licenses/by-nc/4.0. 